\title{
R450A and R513A as lower GWP mixtures for high ambient temperature countries: experimental comparison with R134a
}

Pavel Makhnatch $^{a *}$, Adrián Mota-Babiloni ${ }^{b}$, Alejandro López Belchíc, Rahmatollah Khodabandeh $^{\mathrm{a}}$

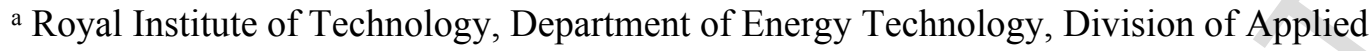
Thermodynamics and Refrigeration, Brinellvägen 68, 10044 Stockholm, Sweden

${ }^{\mathrm{b}}$ ISTENER Research Group, Department of Mechanical Engineering and Construction, Universitat Jaume I, Campus de Riu Sec s/n, E-12071 Castellón de la Plana, Spain

${ }^{c}$ Engineering and Applied Technologies Department, University Centre of Defence at the Spanish Air Force Academy, Ministry of Defense-Technical University of Cartagena. C/Coronel Lopez Peña, s/n, 30720, Santiago de la Ribera, Murcia, Spain

\begin{abstract}
In recognition of the impact of the refrigeration sector on climate change, global commitments are achieved to replace hydrofluorocarbon substances with more planet-friendly alternatives. In this regard, countries with high ambient temperatures (HAT) face additional problems in identifying suitable alternatives due to the impact of such temperatures on energy performance in vapor compression systems. This paper presents an experimental analysis using R134a and two lower global warming potential (GWP) mixtures in a small capacity vapor compression refrigeration system for HAT environments. The range of evaporating and condensing conditions was selected to simulate a refrigeration system working at HAT conditions. The experimental operating results show that although R450A values are acceptable, R513A shows better adaptation to refrigeration system in terms of pressure ratio, discharge temperature and mass flow rate. Then, attending to experimental energetic results, R450A energy performance (quantified by COP) and cooling capacity is lower than R513A and R134a. TEWI analysis of a small refrigeration unit shows $\mathrm{CO}_{2}$ equivalent emission saving when using $\mathrm{R} 450 \mathrm{~A}$ in the different condensation conditions. However, taking into account the variation of cooling capacity, R513A system results in the lowest TEWI when normalizing per unit of delivered cooling capacity.
\end{abstract}

Keywords: HFC HFO mixtures, energy performance, high ambient temperature (HAT), vapor compression system, refrigerants, drop-in replacement

\section{Nomenclature}

* Corresponding Author:

Tel: +4687906885

E-mail address: pavelma@kth.se 
$c_{p} \quad$ specific heat at constant pressure $\left(\mathrm{kJ} \mathrm{kg}^{-1} \mathrm{~K}^{-1}\right)$

$c_{v} \quad$ specific heat at constant volume $\left(\mathrm{kJ} \mathrm{kg}^{-1} \mathrm{~K}^{-1}\right)$

COP coefficient of performance (-)

$D \quad$ pipe inner diameter (m)

$E_{\text {annual }}$ annual energy use $\left(\mathrm{kWh} \mathrm{y}^{-1}\right)$

$h \quad$ enthalpy $\left(\mathrm{kJ} \mathrm{kg}^{-1}\right)$

$L \quad$ leakage rate $\left(\mathrm{kg} \mathrm{y}^{-1}\right)$

$m \quad$ refrigerant charge $(\mathrm{kg})$

$\dot{m}_{\text {ref }} \quad$ refrigerant mass flow rate $\left(\mathrm{g} \mathrm{s}^{-1}\right)$

$n \quad$ refrigeration system operating time (y)

$P_{\text {comp }}$ motor-compressor electrical power consumption (W)

$\dot{Q}_{\text {evap }}$ cooling capacity (W)

$T \quad$ temperature $\left({ }^{\circ} \mathrm{C}\right)$

$v \quad$ refrigerant velocity $\left(\mathrm{m} \mathrm{s}^{-1}\right)$

VCC volumetric cooling capacity $\left(\mathrm{J} \mathrm{m}^{-3}\right)$

wt $\%$ percentage by weight

Greek

$\alpha \quad$ recovery/recycling factor (-)

B $\quad \mathrm{CO}_{2}$-emission factor $\left(\mathrm{kg} \mathrm{kWh}^{-1}\right)$

$\rho \quad$ density $\left(\mathrm{kg} \mathrm{m}^{-3}\right)$

Subscripts

in inlet 


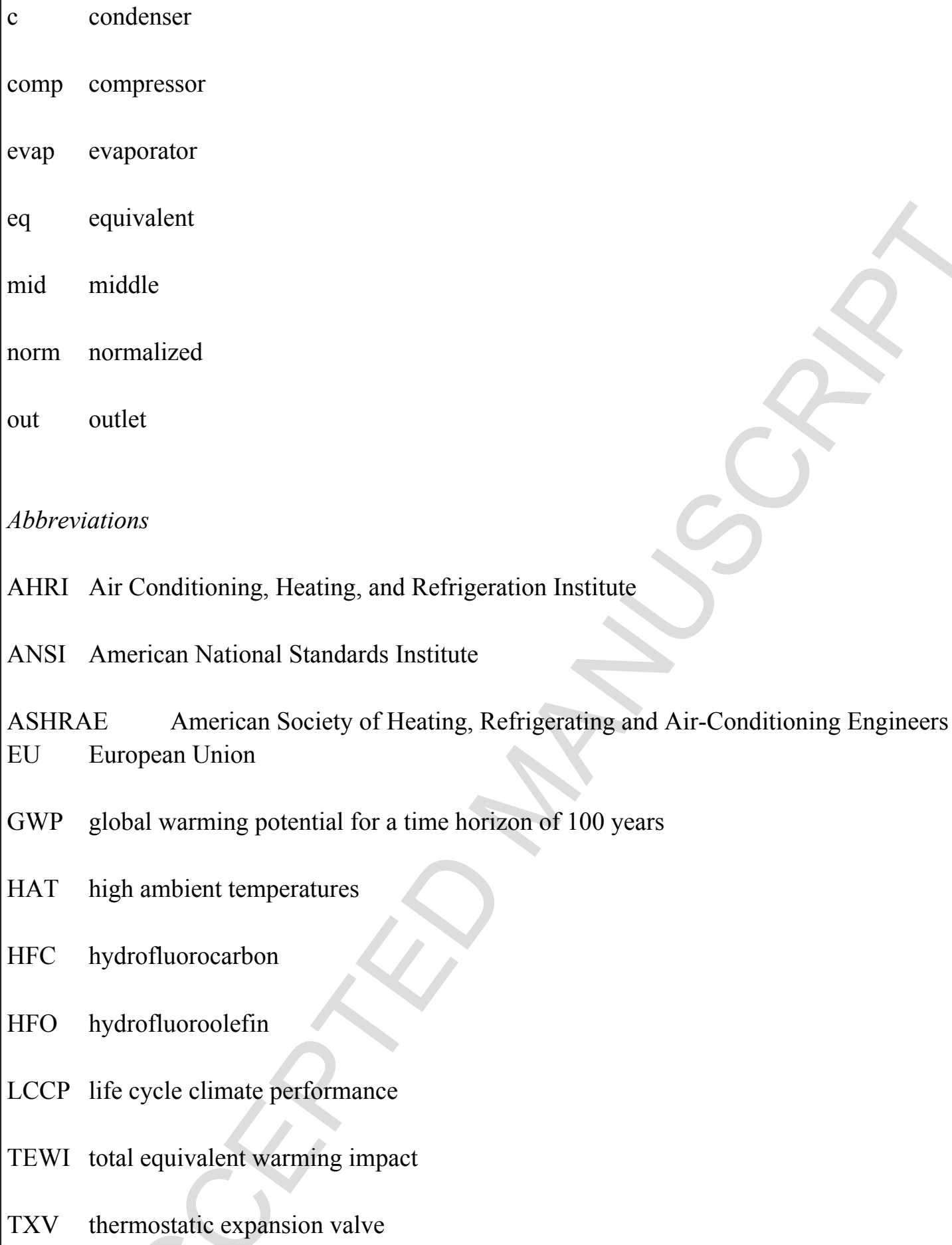

AHRI Air Conditioning, Heating, and Refrigeration Institute

ANSI American National Standards Institute

ASHRAE American Society of Heating, Refrigerating and Air-Conditioning Engineers EU European Union

GWP global warming potential for a time horizon of 100 years

HAT high ambient temperatures

HFC hydrofluorocarbon

HFO hydrofluoroolefin

LCCP life cycle climate performance

TEWI total equivalent warming impact

TXV thermostatic expansion valve

\section{Introduction}

There is a long-term trend of global mean temperature increase since the beginning of the industrial revolution. In the 136-year record history, 17 of the 18 warmest years have occurred during the current century; largely as a result of the increased carbon dioxide and other humanmade greenhouse gases emissions (GISTEMP Team, 2018). The International Institute of Refrigeration estimates that $7.8 \%$ of global greenhouse gas emissions are accounted to refrigeration sector, heat pumps and cryogenics. More than a third of them are direct emissions 
of fluorinated refrigerants, whereas the rest is related to the production of energy required to drive refrigeration systems (IIR/IIF, 2017). In order to limit the global climate change to a temperature increase of $2{ }^{\circ} \mathrm{C}$, fluorinated substances are being controlled by a number of environmental protection regulations and their consumption has to be significantly reduced in the future both in the European Union (European Parliament and the Council of the European Union, 2014) and worldwide (Ozone Secretariat, 2018).

In the European Union (EU), a regulatory action has been taken to control hydrofluorocarbons (HFCs) and other fluorinated gases through the EU Regulation No 517/2014 (European Parliament and the Council of the European Union, 2014). The target is to reduce by $79 \%$ the volume of HFCs placed on the market in comparison with 2009-2012 levels. Outside the European Union, some developed countries (e.g. Japan, New Zealand, Switzerland, the USA) have performed efforts in the low GWP refrigerants promotion. In the case of the USA, which is the country with highest HFCs emissions level among all the developed countries (United Nations, 2018), the US Environmental Protection Agency is including fluids with reduced GWP in the list of acceptable substances, and retiring those for which the substitutes that pose less overall risk to human health and the environment are available (US EPA, 2017).

Globally, the recent amendment of the Montreal Protocol, which will enter into force on January the $1^{\text {st }} 2019$, has included HFCs to the list of controlled substances and sets the phase-down schedule for their use. During the development of the legislation, the concern has been expressed whether suitable alternatives to high GWP HFC refrigerants for air-conditioning applications are available and adequately demonstrated under conditions of high ambient temperatures (HAT) (Seidel et al., 2016). As a result, a group of HAT countries has received a delay in the HFC reduction schedule (Ozone Secretariat, 2018).

$\mathrm{R} 134 \mathrm{a}$ is identified as a dominant contributor to global warming among all the hydrofluorocarbons (Intergovernmental Panel on Climate Change, 2014). R134a presents a global warming potential (GWP) of 1300 and is a fluorinated refrigerant used in air conditioning and refrigeration systems. The R134a high critical temperature $\left(101.1^{\circ} \mathrm{C}\right)$ allows its use at acceptable energy performance and discharge temperatures in HAT countries, where higher condensing temperatures are observed in vapor compression systems. Despite R134a high GWP, its use is being still increased in developing countries as an R12 retrofit replacement (Hu et al., 2010). According to the UNEP estimates, the global production of HFCs is dominated by the production of R134a (223 ktonnes), of which 123 ktonnes are produced in developing countries (UNEP Technology and Economic Assessment Panel, 2015). Therefore, the reduction of R134a use is necessary in order to achieve the global environmental goals.

A limited number of studies have investigated the performance of R134a alternatives at high condensation temperatures. Ribeiro (2016) developed a prototypal single-stage vaporcompression for the refrigeration of electronics equipment at telecommunication stations. Mastrullo et al. (2016), theoretically compared R134a with two HFOs, R1234yf and R1234ze(E), 
in an air-conditioned high-speed train compartment at summer and winter conditions. Their study proves that the coefficient of performance (COP) difference between baseline and alternative fluids strongly depends on the ambient temperature.

Among the different viable candidates to replace R134a, natural refrigerants are flammable (e.g. isobutane) or operate at excessive pressures $\left(\mathrm{CO}_{2}\right)$. Out of the synthetic refrigerants, hydrofluoroolefins (HFOs) R1234yf and R1234ze(E) are used as alternatives to R134a (Devecioğlu et al., 2018). Hovewer, their applicability is limited due to the flammability characteristics of both HFOs. Meanwhile, HFC/HFO mixtures are technically seen as possible substitutes (Mota-Babiloni et al., 2015a). R1234yf (Aprea et al. 2017a) and R1234ze(E) (Aprea et al., 2017b) are considered as components in a HFO/HFC mixture, where up to $90 \mathrm{wt} \%$ of HFO has been considered in their composition to obtain blends with low GWP values.

Several authors have explored non-flammable HFC/HFO mixtures suitable for R134a replacement: Mota-Babiloni et al. (2015b) studied the use of R450A as a non-flammable and nontoxic alternative to R134a in applications where the use of pure HFOs such as R1234yf or R1234ze is not possible. Later, Mendoza-Miranda et al. (2016) have performed a comparative energetic evaluation of R450A with R134a and two other pure HFOs. Kontomaris et al. (2013) studied the use of R513A in a chiller designed to operate with R134a, registering similar energy efficiencies and a $0.6 \%$ higher energy consumption. Mota-Babiloni et al. (2017a) measured higher R513A performances in terms of greater cooling capacity and on average 5\% higher COP at low evaporating and condensing temperatures in a vapor compression refrigeration cycle replacing R134a. HFC/HFO mixtures has been lately experimentally investigated in a household refrigerator by Aprea et al. (2018) indicating lower global warming impact of these fluids. Besides, analysis of exergy efficiency and destruction using experimental data also confirms the viability of R450A and R513A to substitute R134a in existing installations (Gill et al. 2018)(Mota-Babiloni et al. 2018), given that no significant difference between these refrigerants have been detected in regard to their compatibility with typical polymers (Eyerer et al., 2018).

Comparable or higher energy efficiency is always a desirable when replacing working fluids of vapor compression systems. It has a direct influence on energy use, and hence on $\mathrm{CO}_{2}$ indirect emissions by fossil fuel burning for electricity production (Aprea and Maiorino, 2011). This fact is especially critical at HAT conditions, because of the acceleration of performance degradation as the condensing temperature increases (Joudi and Al-Amir, 2014).

One of the most relevant drawbacks for the utilization of HFC/HFO mixtures at HAT is the lack of results for these fluids in vapor compression systems at such conditions. These drop-in tests are necessary for the immediate adoption of lower GWP alternatives because the availability of components for the new fluids is still questionable by regional manufacturers (Leportier, 2018).

This paper presents an evaluation of the operation of a small capacity refrigeration test bench using two HFC/HFO mixtures alternatives to R134a through a thermodynamic assessment, an 
experimental comparison and an environmental analysis under HAT conditions. Thus, the main parameters experimentally studied are those affecting system adaptation to the new refrigerants (compression pressure ratio, compressor discharge temperature, refrigerant mass flow and pipeline velocities) and the energy performance (refrigerating effect, volumetric cooling capacity, cooling capacity, compressor power consumption and coefficient of performance, COP). The conditions studied are those typical for vapor compression systems of developing HAT countries, where the use of $\mathrm{R} 134 \mathrm{a}$ is growing, i.e. 40,50 and $60{ }^{\circ} \mathrm{C}$ condensing temperature.

\section{Overview of studied refrigerants}

Refrigerants R450A and R513A are non-flammable substances that are considered to replace R134a with minor system modifications. Both are blends of R134a with an HFO: R1234ze(E) in case of R450A, and R1234yf in case of R513A. Due to the difference in components and composition, the thermodynamic properties of both fluids are relatively different. Table 1 shows the main properties of both mixtures and R134a.

Both alternatives are classified as A1 safety class: lower toxicity refrigerants with no flame propagation when tested at $60{ }^{\circ} \mathrm{C}$ at $101.3 \mathrm{kPa}$, same as for R134a (ASHRAE, 2016). Their GWP is more than two times lower than that of R134a, thus providing lower direct greenhouse emissions when using these alternatives. Their relative molar mass is increased and thus will affect parameters like enthalpy of vaporization, density and viscosity. Critical temperature of $\mathrm{R} 513 \mathrm{~A}$ has $4.6{ }^{\circ} \mathrm{C}$ lower value, compared to R134a, whereas R450A has $3.4{ }^{\circ} \mathrm{C}$ higher critical temperature. The highest critical temperature of R450A suggests lower energy performance deterioration at HAT conditions.

The lowest R450A vapor density will affect the volumetric refrigeration capacity such as, taking into account its lower latent heat of vaporization, a reduction in cooling capacity can be expected for a given compressor using R450A as a replacement to R134a. The cooling capacity of R513A system will be a result of effect of the increased refrigerant vapor density, but reduced latent heat of vaporization of this refrigerant.

Critical pressure of the alternatives is reduced and thus their use will not lead to additional pressure stress to the equipment designed to be used with R134a. The normal boiling point of R513A is slightly lower than that of R134a, so it can be considered for all applications where this conventional refrigerant is used. Furthermore, slightly higher evaporating temperatures should be allowed for R450A to avoid the risk of system air infiltration at temperatures below $-23.35{ }^{\circ} \mathrm{C}$. Unlike R134a, both alternatives have temperature glide and therefore the further comparison is made at equivalent middle evaporating and middle condensing temperatures. These parameters represent the average of temperatures at evaporator inlet and saturated vapor temperature in the evaporator and the average of saturated liquid and saturated vapor temperatures in the condenser, respectively. However, this consideration mostly applies to R450A, since R513A behavior can be 
approximated to that of a pure substance due to its negligible temperature glide and the existence of an azeotropic temperature $\left(27.0^{\circ} \mathrm{C}\right)$.

Table 1. Main characteristics of R134a and its alternatives (Lemmon et al., 2013)

\begin{tabular}{|c|c|c|c|}
\hline & R134a & R513A & R450A \\
\hline \multirow{2}{*}{ Composition } & pure & R134a/1234yf & R134a/R1234ze(E) \\
\hline & $\mathrm{R} 134 \mathrm{a}$ & $44 / 56 \mathrm{wt} \%$ & $42 / 58 w t \%$ \\
\hline ANSI/ASHRAE Standard safety classification & A1 & A1 & A1 \\
\hline $\mathrm{GWP}_{100-\mathrm{yr}}{ }^{\mathrm{a}}$ & 1300 & 572 & 547 \\
\hline Average molar mass, $\mathrm{kg} \mathrm{mol}^{-1}$ & 102.03 & 108.43 & 108.69 \\
\hline Critical temperature, ${ }^{\circ} \mathrm{C}$ & 101.06 & 94.9 & 104.47 \\
\hline Critical pressure, $\mathrm{MPa}$ & 4.06 & 3.65 & 3.82 \\
\hline Boiling point at $0.1 \mathrm{MPa},{ }^{\circ} \mathrm{C}$ & -26.36 & -29.82 & -23.35 \\
\hline Glide at $0.1 \mathrm{MPa},{ }^{\circ} \mathrm{C}$ & 0.00 & 0.10 & 0.61 \\
\hline Latent heat of vaporization ${ }^{\mathrm{b}}, \mathrm{kJ} \mathrm{kg}^{-1}$ & 198.6 & 175.9 & 188.8 \\
\hline Liquid density ${ }^{\mathrm{b}}, \mathrm{kg} \mathrm{m}^{-3}$ & 1294.8 & 1221.9 & 1259.6 \\
\hline Vapor density ${ }^{\mathrm{b}}, \mathrm{kg} \mathrm{m}^{-3}$ & 14.43 & 17.23 & 13.18 \\
\hline Liquid $\mathrm{c}_{\mathrm{p}}{ }^{\mathrm{b}}, \mathrm{kJ} \mathrm{kg}^{-1} \mathrm{~K}^{-1}$ & 1.34 & 1.31 & 1.33 \\
\hline Vapor $\mathrm{c}_{\mathrm{p}}{ }^{\mathrm{b}}, \mathrm{kJ} \mathrm{kg}^{-1} \mathrm{~K}^{-1}$ & 0.90 & 0.92 & 0.89 \\
\hline Liquid thermal conductivity ${ }^{\mathrm{b}}, \mathrm{mW} \mathrm{m}^{-1} \mathrm{~K}^{-1}$ & 92.01 & 79.21 & 86.23 \\
\hline Vapor thermal conductivity ${ }^{\mathrm{b}}, \mathrm{mW} \mathrm{m}^{-1} \mathrm{~K}^{-1}$ & 11.51 & 11.74 & 11.70 \\
\hline Liquid viscosity ${ }^{\mathrm{b}}, \mu \mathrm{Pa} \mathrm{s}$ & 266.53 & 227.10 & 264.23 \\
\hline Vapor viscosity $^{\mathrm{b}}, \mu \mathrm{Pa} \mathrm{s}$ & 10.73 & 10.51 & 11.16 \\
\hline
\end{tabular}

a Intergovernmental Panel on Climate Change (2014)

${ }^{\mathrm{b}}$ At saturation, at $0^{\circ} \mathrm{C}$

Liquid density of the alternative refrigerants is lower than that of R134a, which contributes to lower pressure drop in the liquid line of the system. Vapor density of the analyzed refrigerants are different and thus influence the mass flow of refrigerants through the fixed speed compressor with constant swept volume. As a result, the mass flow of R513A is expected to be increased, compared to that of R134a, and thus will also contribute to increasing pressure drop in the liquid line.

Liquid specific heats of alternative refrigerants are lower than R134a value. This contributes to an increase of the subcooling area in the condenser if the alternatives are operated with the same subcooling degree as R134a. Thermal conductivity values affect heat transfer in components of a refrigeration system. Hence, the lower liquid thermal conductivity of refrigerant alternatives leads to generally lower heat transfer in heat exchangers, whereas slightly increased vapor thermal conductivity has a slight contribution to heat transfer. 
R513A has the lowest values of liquid and vapor viscosity which contributes to lowering the pressure drop in heat exchangers and system pipelines, compensating for the opposite effect of its increased suction density. Liquid viscosity of R450A is only marginally lower than R134a, whereas its vapor viscosity is the highest.

Then, to observe the behavior at the different operating conditions, theoretical vapor compression cycle simulations were performed using the refrigerant property data obtained from REFPROP 9.1 database (Lemmon et al., 2013). The modelled cycle consists of an evaporator, a compressor, a condenser and an expansion device. The modelled conditions assume constant evaporating/condensing pressures, equivalent to middle evaporating temperatures of $-10,0$ and $10{ }^{\circ} \mathrm{C}$, as well as middle condensing temperatures of 40 and $60{ }^{\circ} \mathrm{C}$. Compressor isentropic efficiency is set to 0.75 and no volumetric loss is assumed. Superheating degree is $11.5{ }^{\circ} \mathrm{C}$ and subcooling degree is $10{ }^{\circ} \mathrm{C}$. Further assumptions are: no pressure loss in pipelines and heat exchangers; isenthalpic refrigerant expansion process. The example of the modelled cycle at the $0 / 60{ }^{\circ} \mathrm{C}$ middle evaporating/condensing temperatures are plotted in logarithmic pressure-enthalpy charts, as shown in Figure 1.

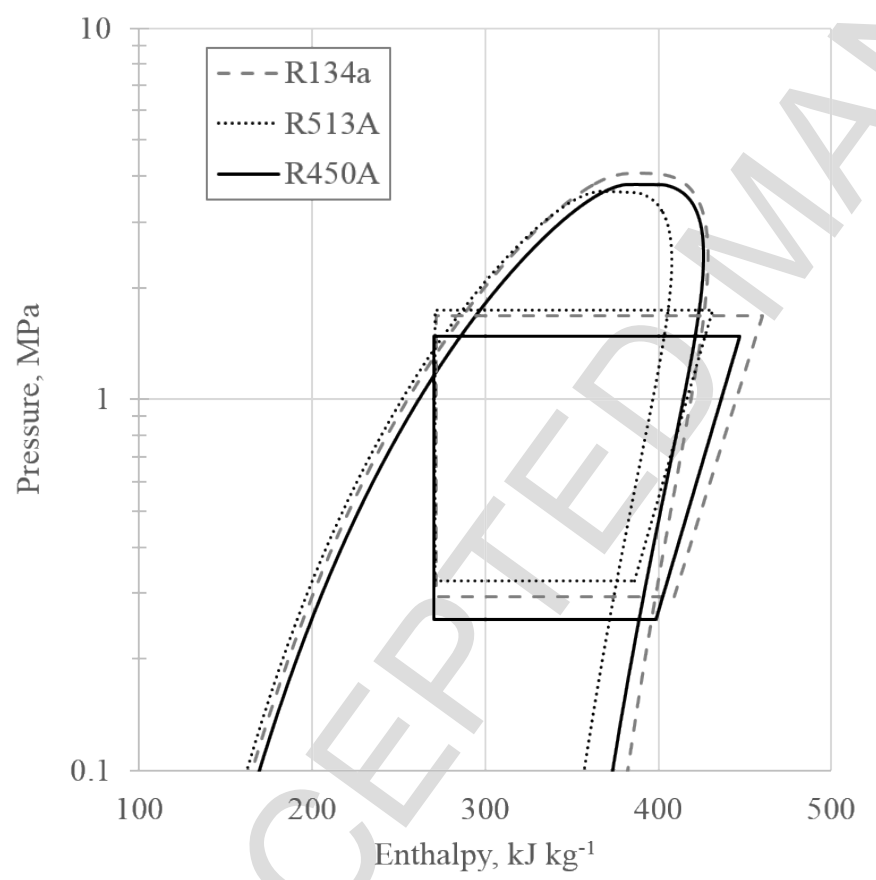

Figure 1. Logarithmic pressure-enthalpy chart for R134a, R450A and R513A.

The modelled results for higher middle condensing temperature are compared to that for lower middle condensing temperature and presented as a respective ratio of coefficient of performance (COP), Figure $2 a$, and volumetric cooling capacity (VCC), Figure $2 b$, for the three analyzed refrigerants. 


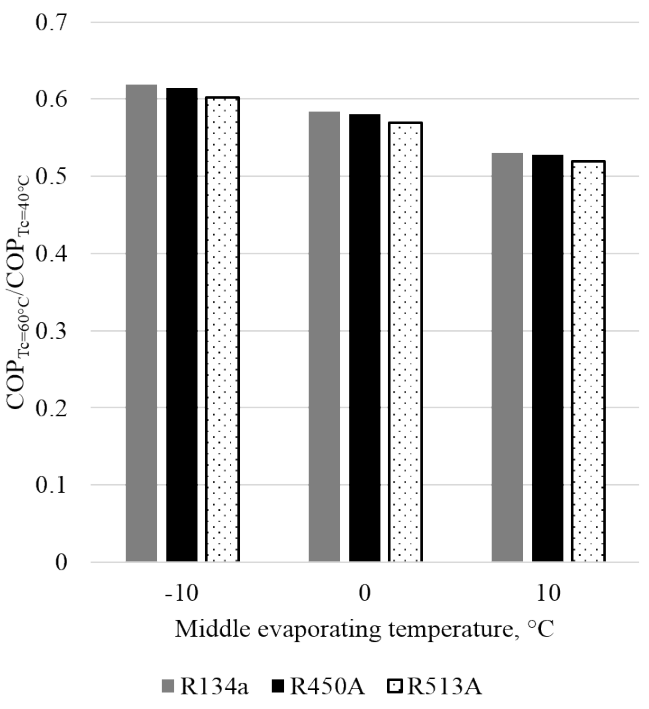

a)

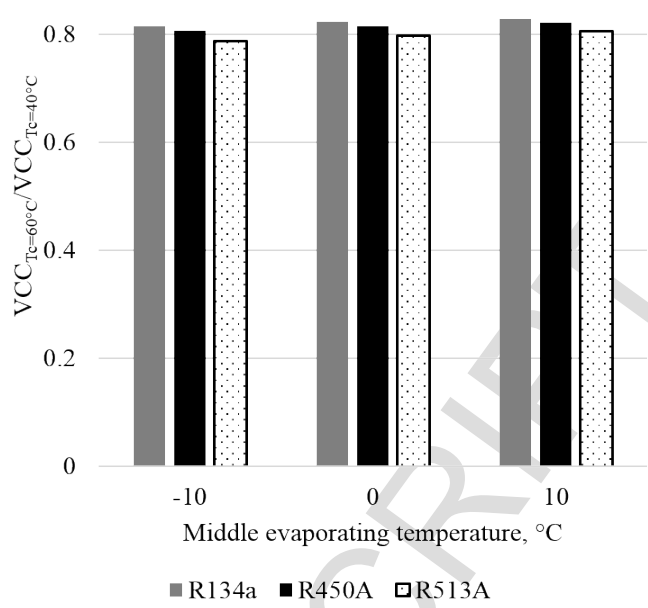

b)

Figure 2. COP (a) and VCC (b) variation caused by condensing temperature increase.

This simulation shows that R513A is more impaired by high condensing temperatures since its $\mathrm{COP}_{\mathrm{Tc}=60^{\circ} \mathrm{C}}$ is between 40 and $48 \%$ lower and $\mathrm{VCC}_{\mathrm{Tc}=60^{\circ} \mathrm{C}}$ between 19 and $21 \%$ lower than that $40{ }^{\circ} \mathrm{C}$ of condensation. The major depletion for R513A is caused by the greatest decrease in refrigerating effect. The situation for R450A is more similar to that of R134a, and the maximum difference between the deviations of both fluids is observed at low evaporating conditions, 0.4 and 0.9 percentage points difference in COP and VCC decrease, respectively. Since the numerical model cannot represent all the complexity of real system operation and interaction, the experimental investigation is conducted in order to have a more accurate observation of the effects of high condensation temperatures onto system operation and energy performance.

\section{Methodology}

\subsection{Experimental setup}

The experimental apparatus used in this study is a small capacity vapor compression refrigeration system with a designed cooling capacity of $1.83 \mathrm{~kW}$, as presented in Figure 3. A system of these characteristics can represent the operation of refrigeration applications as vending machines, water coolers, stand-alone retail food refrigeration units, small capacity stationary and mobile air conditioners. 


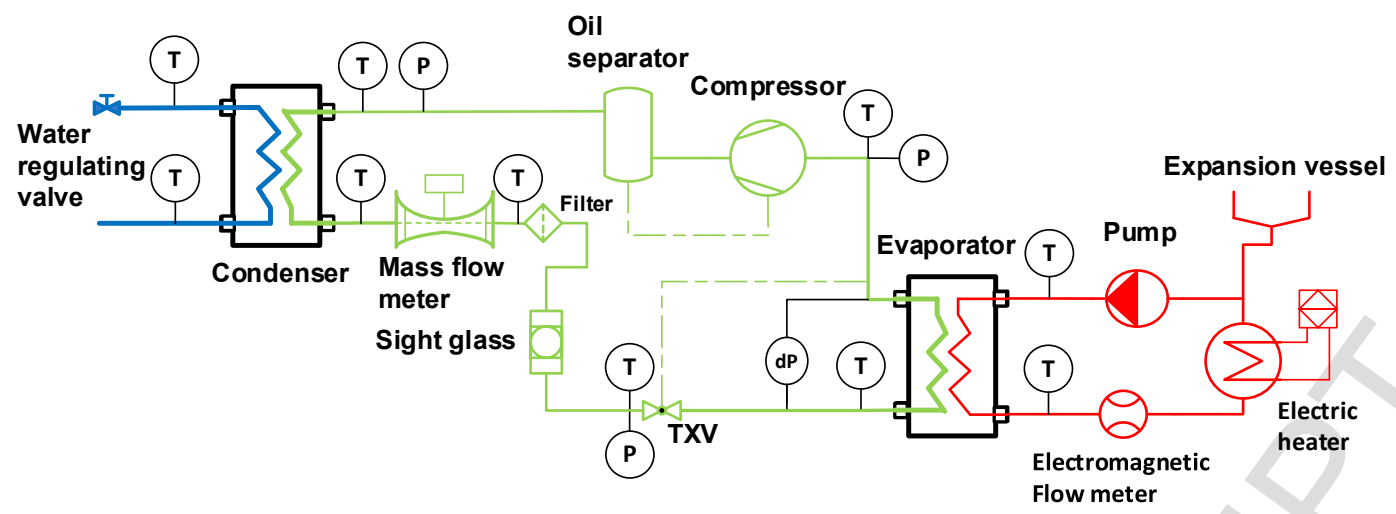

Figure 3. Schematic diagram of the experimental test bench

The main refrigeration circuit of the system consists of a fully hermetic rotary compressor with a motor rating of $550 \mathrm{~W}$ nominal power and a displacement of $2.63 \mathrm{~m}^{3}$ per hour that was originally designed for R134a. The polyolester oil (grade 32) is used in the compressor and its return to the compressor is ensured by the usage of an oil separator. Both, the evaporator and the condenser, are plate heat exchangers designed to work with R134a. The amount of refrigerant flowing into the evaporator is controlled by the R134a thermal expansion valve (TXV). The heat load to the evaporator is supplied by a glycol/water brine close loop (43 wt $\%$ ethylenglycol) with a constant speed pump and a controlled heater. The condenser is cooled by an open tap water loop with a controlled valve to maintain the condenser pressure at a set level.

The measuring sensors and instruments used are: $T$ type thermocouples used to measure the temperatures at the inlet and the outlet of each main component (main and secondary circuits); two calibrated pressure sensor transducers used to measure the condensation (2.1 MPa range) and evaporation (0.7 MPa range) pressures; pressure transmitter used to measure pressure before the TXV (1.8 MPa range); a differential pressure transducer used to measure the refrigerant pressure difference between evaporator inlet and outlet; a Coriolis type flow meter used to measure the refrigerant mass flow; a two configurable multi transducers used to measure the electric consumption of motor-compressor set and the heaters. Finally, all the measurements are collected by a data acquisition system and gathered to a personal computer, in which the data is displayed and registered. It should be noted that the components and the pipes of the system are completely insulated to minimize losses to ambient and allow measuring more accurate results.

The uncertainties of the directly measured parameters correspond to the individual uncertainties of the measurement equipment, Table 2. The uncertainties of the calculated parameters are evaluated following the methodology of Moffat (1988) and stated in the following chapter. These values do not include the uncertainties of the enthalpy estimation in REFPROP v9.1 database.

Table 2. Uncertainties of sensors used

\begin{tabular}{lll}
\hline Variable & Sensor & Uncertainty \\
\hline Temperature & T type thermocouples & $\pm 0.1^{\circ} \mathrm{C}$ \\
Pressure & Pressure transducer & $\pm 0.08 \%$ full scale best straight line
\end{tabular}




\begin{tabular}{lll} 
Pressure & Pressure transmitter & $\pm 0.2 \%$, span \\
Differential pressure & Differential pressure transducer & $\pm 0.25 \%$, reading \\
Mass flow & Coriolis & $\pm 0.5 \%$, reading \\
Electric power & Multivariable transducers & $\pm 0.2 \%$, reading \\
\hline
\end{tabular}

\subsection{Tests conditions}

The performed tests are intended to cover most of the observable operating conditions of typical system operating in warmer countries. Hence, eighteen data points have been measured for each of the three analyzed refrigerants representing three middle condensing temperatures over a range of middle evaporating temperatures from $-10{ }^{\circ} \mathrm{C}$ to $15^{\circ} \mathrm{C}$ (with $5{ }^{\circ} \mathrm{C}$ step), Table 3 . The maximum deviation from the target values for condensing temperature at different evaporating temperatures was $0.1{ }^{\circ} \mathrm{C}$. The standard deviations of superheating and subcooling degree were $0.1{ }^{\circ} \mathrm{C}$ and 0.5 ${ }^{\circ} \mathrm{C}$, respectively.

Table 3. Tests operating conditions.

\begin{tabular}{lccc}
\hline Operating conditions & R134a & R450A & R513A \\
\hline Condensing temperatures, ${ }^{\circ} \mathrm{C}$ & \multicolumn{3}{c}{$[40,60]$ at steps of 10} \\
Evaporating temperatures, ${ }^{\circ} \mathrm{C}$ & {$[-10,15]$ at steps of 5} \\
Average measured superheating degree, ${ }^{\circ} \mathrm{C}$ & 11.5 & 11.5 & 11.4 \\
Average measured subcooling degree, ${ }^{\circ} \mathrm{C}$ & 9.8 & 10.0 & 9.8 \\
\hline
\end{tabular}

A drop-in replacement was performed to introduce the alternative refrigerant as defined in the Air Conditioning, Heating, and Refrigeration Institute (AHRI) Low GWP Alternative Refrigerants Evaluation Program, which allow only minor modifications (AHRI, 2015). In this sense, the refrigerant charge adjustment and the superheating degree regulation through the screw of the thermal expansion valve were the only performed modifications.

Steady state condition was achieved when the maximum deviation of condensing and evaporating pressures was lower than $2.5 \mathrm{kPa}$ and the deviation of all measured temperatures was lower than $0.5 \mathrm{~K}$. Each experimental measurement considered in this study is the average of the last twenty minutes of operation out of thirty minutes of steady state data recording interval. The rest of the steady-state output parameters are obtained using properties given by the REFPROP v9.1 database (Lemmon et al., 2013).

\section{Experimental results and discussion}

In this section, the results of the experimental investigation are shown and discussed. The focus is given to the difference between a set of condensation temperatures (representing different ambient temperatures) and the deviation between R134a and its alternatives. Experimental results using R513A and R450A at lower condensation temperatures can be found at Mota-Babiloni et al. (2017b) and Makhnatch et al. (2017). 


\subsection{Adaptation to the current system}

The compression ratio is the relation between the discharge and the suction pressure. Thus, at a given middle evaporating and middle condensing temperatures, it is depended on the P-T relation at the saturated vapor condition. The tests results for the proposed conditions are shown in Figure 4 (1.5\% maximum measurement propagated uncertainty). It can be observed a notable difference in the established compressor ratio of R450A and R513A when compared to R134a. While the $\mathrm{R} 450 \mathrm{~A}$ compression ratio is comparable to that of $\mathrm{R} 134 \mathrm{a}$ (or up to $3.5 \%$ higher at lower evaporating temperatures), that of R513A is up to $8.9 \%$ lower than that of R134a. Additionally, the increase in pressure ratio is lower for R513A ( $61 \%$ on average) as compared to the other tested refrigerants $(66 \%$ on average). The reduced pressure ratio of $\mathrm{R} 513 \mathrm{~A}$ will be beneficial to the performance of a compressor, whereas the R450A performance at lower evaporating temperatures will be penalized by a slight increase in compression pressure ratio at such conditions.

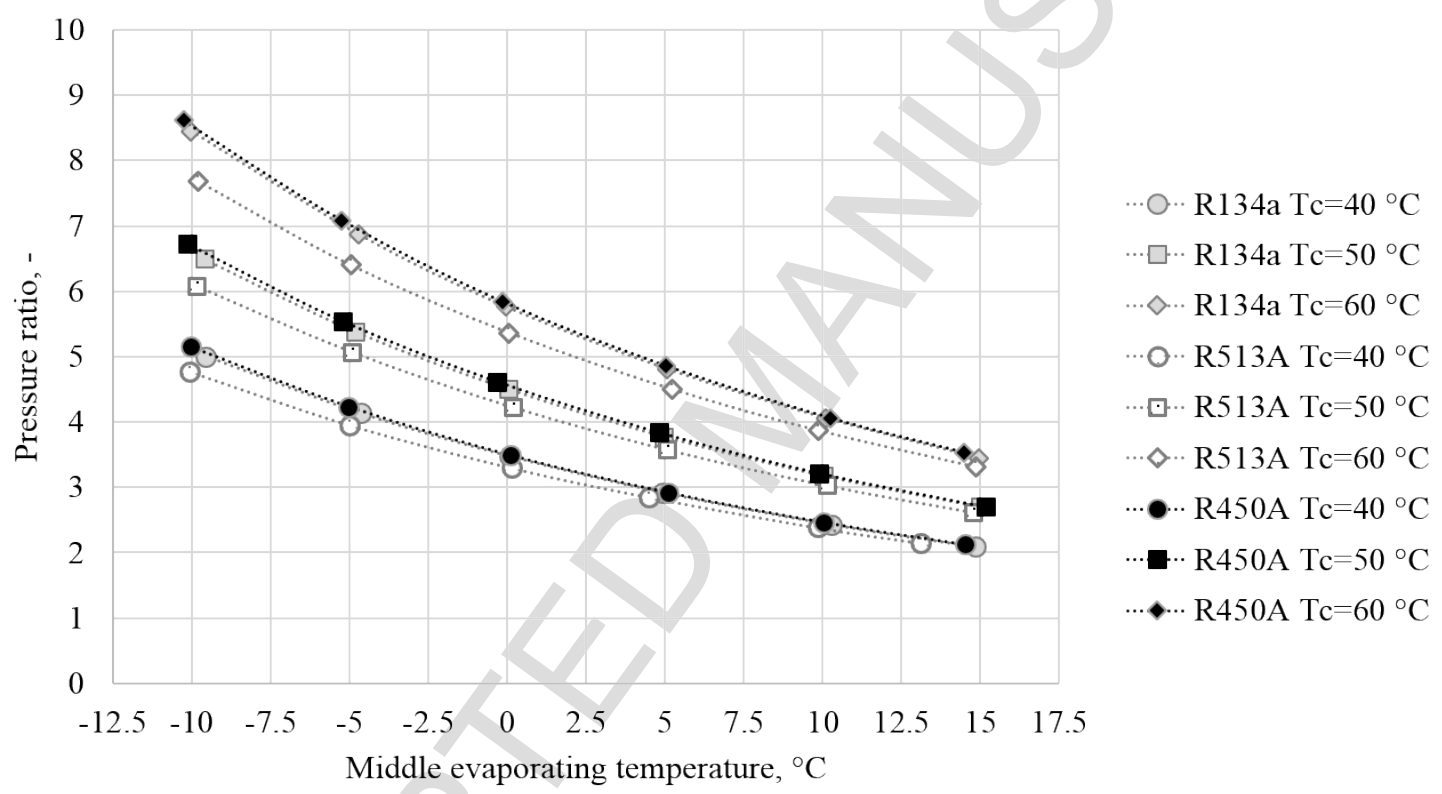

Figure 4. Compression pressure ratio for the studied refrigerants

The discharge temperature is a critical parameter under HAT operation where high compression ratios and high compressor discharge temperatures are observed. High discharge temperatures should be avoided because can damage the compressor and compromise its reliability. Besides, the fluid and components reactivity is empowered at high temperatures which could degrade the oil prematurely, decreasing the performance of the compressor and thus the COP. Therefore, operation with discharge temperatures above $115{ }^{\circ} \mathrm{C}$ is not recommended by the compressor manufacturer.

The compressor discharge temperature represents the heat absorbed in the process of compression, evaporation and circulation in the suction line. Therefore, it depends on thermophysical properties of the refrigerant, mainly vapor specific heat; the operating conditions (the evaporating and condensing temperatures, superheating degree) and the compressor characteristics. Figure 5 
shows the discharge temperature measured in the insulated discharge line, where the thermocouple is located.

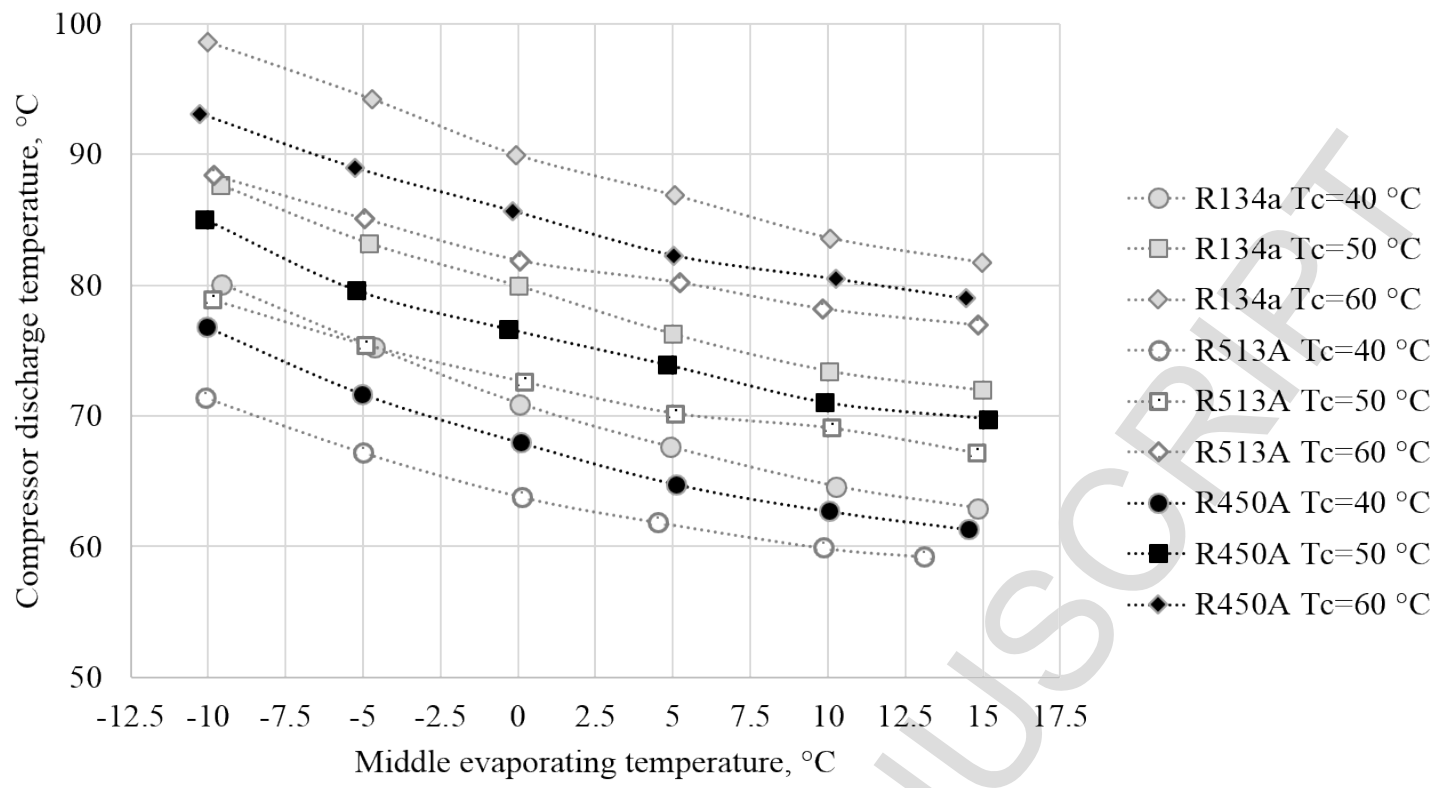

Figure 5. Compressor discharge temperature of R134a and the two lower GWP alternatives at different condensation temperatures.

According to the experimental recorded values, R134a presents the higher compressor discharge temperature in all the condensing temperatures tested. The two lower GWP alternatives present slightly lower discharge temperatures. The maximum discharge temperature of 98.6, 93.1 and $88.4{ }^{\circ} \mathrm{C}$ have been observed for $\mathrm{R} 134 \mathrm{a}, \mathrm{R} 450 \mathrm{~A}$ and R513A refrigerants, respectively. In consequence, the system operating range can be enlarged when using alternatives due to their lower discharge temperature at the same conditions.

The main properties of the refrigerants, Table 1, suggest that the difference in their vapor density and saturated vapor pressures will lead to the difference of their mass flow values. This difference will have a direct effect on their transport properties, as well as the COP and cooling capacity of the system using such refrigerants. The directly measured mass flow values are presented in Figure 6. 


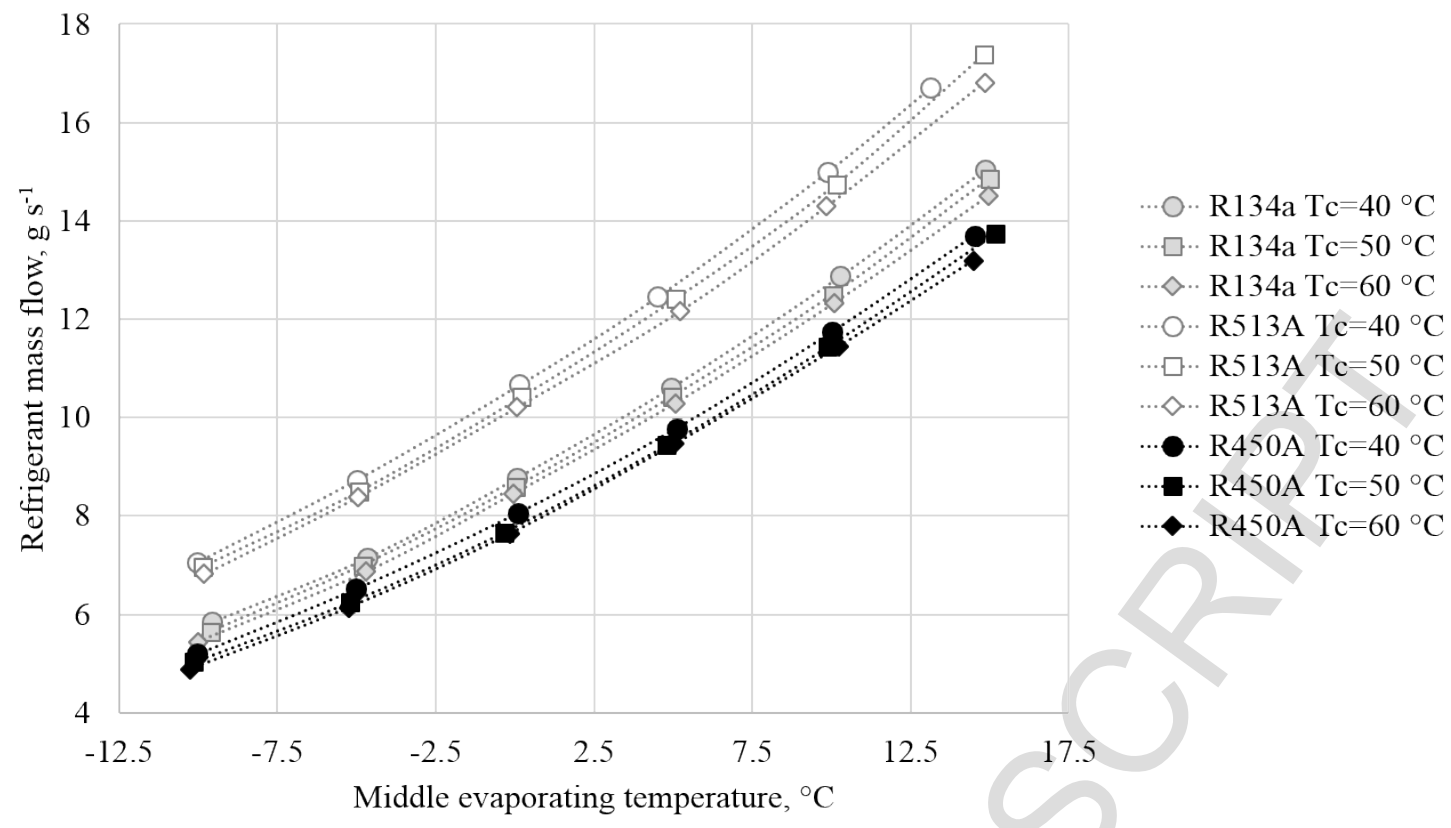

Figure 6. Experimental mass flow rate at the tested conditions.

The noticeable reduction of mass flow of R450A, around a $9.2 \%$ of that of R134a, is observed as a result of reduced compressor suction density over an entire range of analyzed conditions. On the contrary, the mass flow of R513A is $19.3 \%$ higher, on average, than that of R134a. The change of mass flow values is in line with the difference in refrigerant vapor density at compressor suction point, given the constant swept volume of the compressor. At comparable middle evaporating temperatures, the mass flow rate values are dependent on compressor volumetric efficiency which is lower at the highest middle condensing temperature condition due to the effect of increased pressure ratio.

The adaptation of the refrigerants to the system is further studied by analyzing the velocities of the working fluids in the main pipelines. At a design stage, feasible velocities in refrigerant lines are established considering such aspects as e.g. pressure drop, noise, oil return, economics. However, the velocities are affected using alternative refrigerants by the different density values. Therefore, suction and discharge vapor lines and liquid line velocities are calculated following Equation 1 and listed in Table 4.

$$
v_{\text {line }}=\frac{4 \cdot \dot{m}_{\text {ref }}}{\rho_{\text {line }} \pi d_{\text {line }}^{2}}
$$

Table 4. Experimental velocity range at the test bench refrigerant lines.

\begin{tabular}{llll}
\hline Pipeline & $\mathrm{R} 134 \mathrm{a}$ & $\mathrm{R} 450 \mathrm{~A}$ & $\mathrm{R} 513 \mathrm{~A}$ \\
\hline Liquid, $\mathrm{m} \mathrm{s}^{-1}$ & {$[0.10,0.27]$} & {$[0.09,0.25]$} & {$[0.13,0.33]$} \\
Vapor (suction line), $\mathrm{m} \mathrm{s}^{-1}$ & {$[5.88,6.98]$} & {$[5.79,6.94]$} & {$[6.06,6.97]$} \\
Vapor (discharge line), $\mathrm{m} \mathrm{s}^{-1}$ & {$[1.65,7.02]$} & {$[1.57,6.90]$} & {$[1.75,6.74]$} \\
\hline
\end{tabular}


The suction line vapor velocities of R450A and R513A are very close to those of R134a and thus will not affect the behavior of the system, whereas their discharge line vapor velocities are lower than those of R134a. The minimum values of discharge line refrigerant vapor velocities are obtained at the lower middle evaporating temperatures due to the lower vapor densities of the compressed refrigerant at such conditions. Further, the discharge line velocities are reduced at higher middle condensing temperatures which can reduce discharge line pressure drop and thus improve refrigeration system performance.

The liquid line refrigerant velocities are affected by a notable variation of liquid density and mass flow between the analyzed refrigerants so that the average liquid line velocity of R513A is $26.3 \%$ greater than that of R134a. The increased velocity of R513A contributes to its greater liquid line pressure drop and thus the attention should be given to possibility of a flash gas formation before TXV at low levels of subcooling degree with increased liquid line pressure drop for this refrigerant.

\subsection{Energy performance results}

This section studies the main energy parameters of the refrigeration system such as refrigerating effect, volumetric cooling capacity, cooling capacity, power consumption and coefficient of performance.

The refrigeration effect is the quantity of heat that each unit mass of refrigerant absorbs from the refrigerated medium. It can be calculated as the refrigerant enthalpy change in the evaporator, Equation 2. The enthalpy at the evaporator outlet is calculated using the low pressure and the evaporator outlet temperature. Besides, the evaporator inlet temperature is calculated considering isenthalpic process at the expansion valve. The observed refrigerating effect values are presented in Figure 7.

$$
q_{\text {evap }}=h_{e v, o u t}-h_{e v, \text { in }}
$$




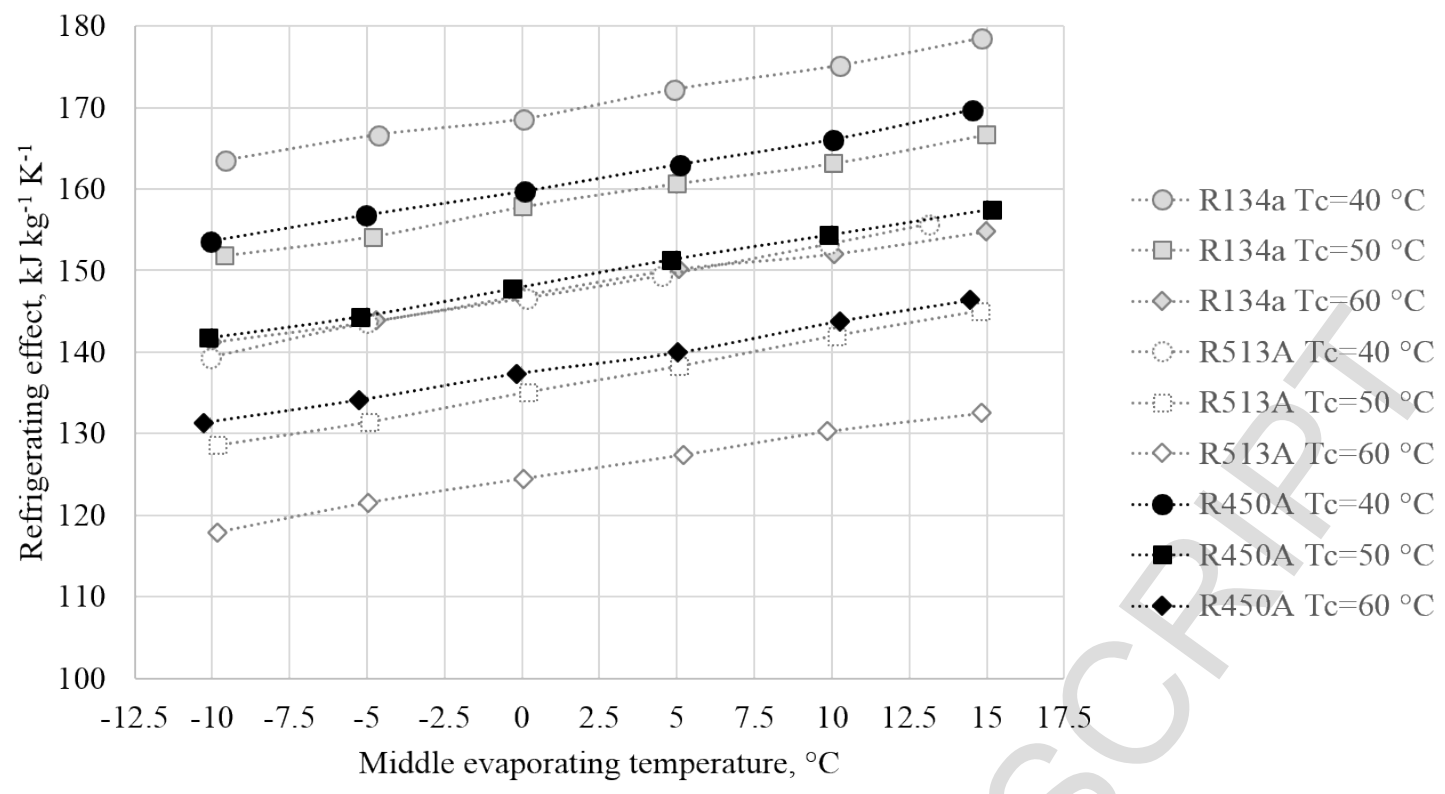

Figure 7. Refrigerating effect at the tested conditions.

The refrigeration effect of alternative refrigerants is reduced in comparison to $\mathrm{R} 134 \mathrm{a}$ as a result of lower vaporization enthalpies, considering the controlled testing conditions. Under the tested conditions, the highest reduction is observed at the lower middle evaporating temperatures and with the increasing middle condensing temperatures. Thus the highest reduction is observed for R513A for which the range of observed reduction values varies from $12.6 \%$ to $16.5 \%$ at $15 / 40{ }^{\circ} \mathrm{C}$ and $-10 / 60{ }^{\circ} \mathrm{C}$ middle evaporating/condensing temperatures. Similarly, the range of observed reduction values for $\mathrm{R} 450 \mathrm{~A}$ varies from $4.7 \%$ to $6.5 \%$ at $15 / 40{ }^{\circ} \mathrm{C}$ and $-10 / 60{ }^{\circ} \mathrm{C}$ middle evaporating/condensing temperatures (the maximum uncertainty of the calculated refrigerating effect is $0.1 \%$ ). Thus, R513A is most affected by the evolution of saturated liquid enthalpy at HATs.

The volumetric cooling capacity (VCC) is the refrigeration effect per unit of swept volume. It can be obtained by the product of the suction density and the refrigerating effect, Equation 3. The suction density at the evaporator outlet is calculated using the low pressure and the evaporator outlet temperature.

$$
V C C=\rho_{\text {suc }} \cdot q_{\text {evap }}
$$

According to the measured results, Figure 8, the observed VCC of refrigerant R513A is superior to the R134a and R450A. In spite of the reduced refrigeration effect of R513A, its VCC is on average $1.5 \%$ greater than that of $\mathrm{R} 134 \mathrm{a}$ as a result of the $18.1 \%$ greater refrigerant vapor density at the compressor suction point. Respective refrigerant vapor density values for R450A are on average $7.0 \%$ lower than that of R134a, which being combined with its lower refrigeration effect results in $13.4 \%$ VCC reduction, on average. The maximum uncertainty of the calculated VCC is $0.1 \%$. 


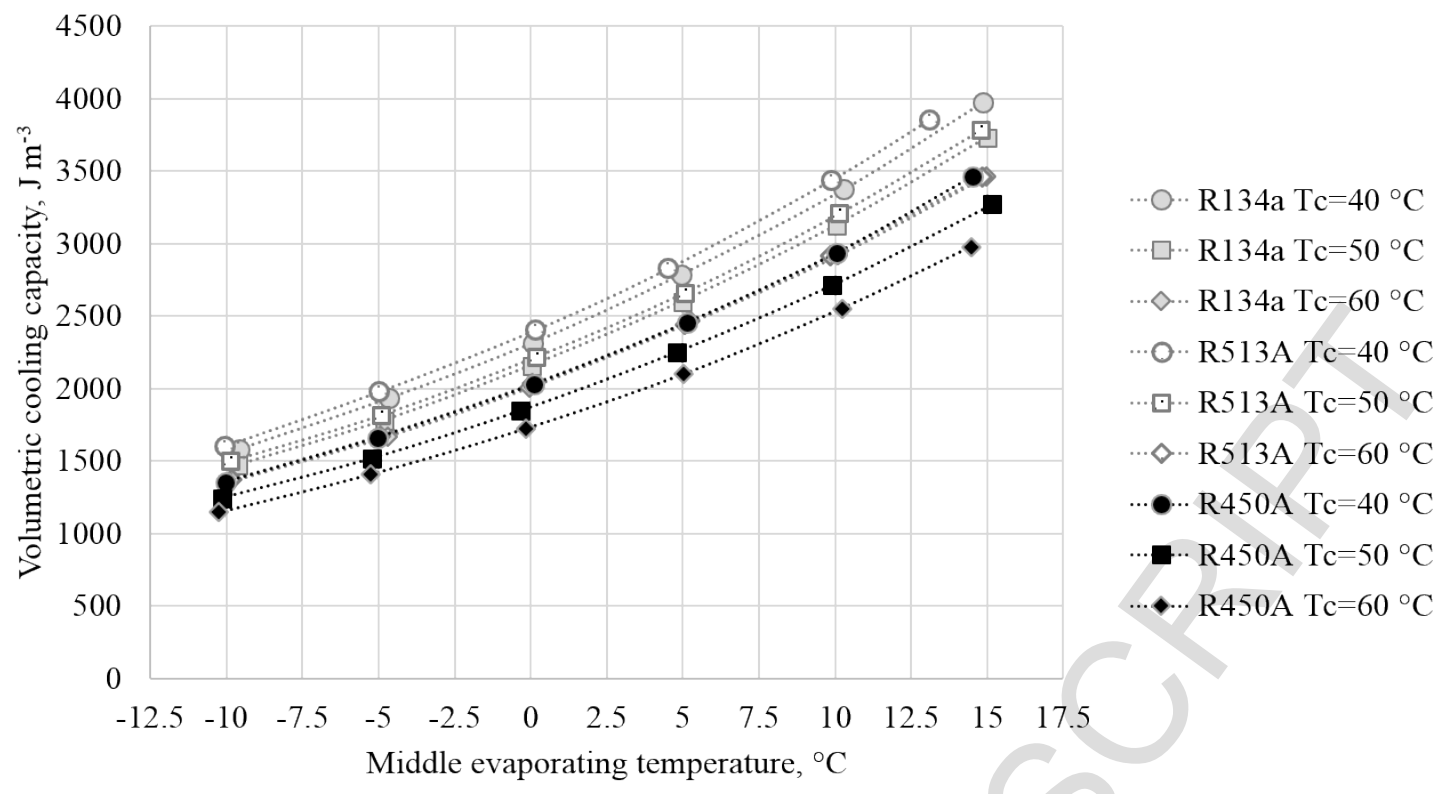

Figure 8 . Volumetric cooling capacity at the tested conditions.

The cooling capacity is the ability of a cooling system to remove heat. Contrary to the VCC, this parameter includes the effect of the compressor volumetric efficiency and the compressor swept volume. It is calculated multiplying the refrigerating effect and refrigerant mass flow rate, directly measured, Equation 4.

$$
\dot{Q}_{\text {evap }}=q_{\text {evap }} \cdot \dot{m}_{\text {ref }}
$$

The measured cooling capacity values are presented in Figure 9. The resulting cooling capacity of $\mathrm{R} 450 \mathrm{~A}$ is $14.3 \%$, on average, lower than that of R134a system, whereas of R513A is, on average, $2.5 \%$ higher. The maximum uncertainty of the calculated cooling capacity is $0.5 \%$.

As it can be observed, the reduced refrigerating effect of R513A is fully compensated by the increase of mass flow of this refrigerant, whereas the slightly increased refrigerating effect of $\mathrm{R} 450 \mathrm{~A}$ is penalized by the reduction in its mass flow. While the cooling capacity reduction is not desired when using alternative refrigerant in existing equipment, this can be addressed in new equipment by appropriate sizing of its components (e.g. compressor). 


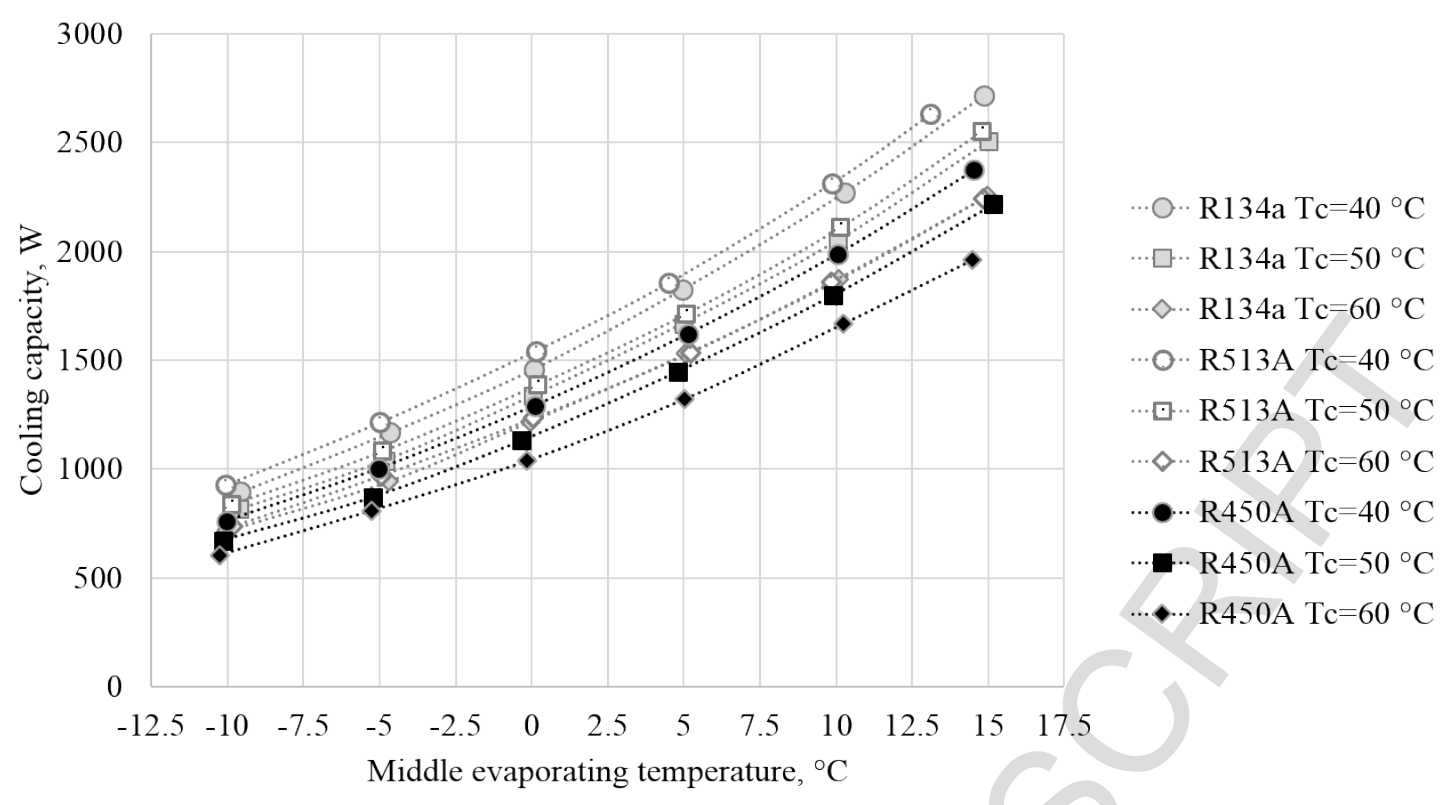

Figure 9. Cooling capacity at the tested conditions.

The increase of the cooling capacity of R513A is marginally greater than that is expected based on the VCC difference observations. Similarly, the decrease in cooling capacity of R450A is marginally lower than expected. This is the effect of the variation in volumetric efficiency of compression, which is influenced by the difference in compression pressure ratio for the analyzed refrigerants. Referring to the diminishing of the cooling capacity at HATs, both alternatives are slightly more affected by HATs and they exhibit $18 \%$ reduction of cooling capacity, compared to the $17 \%$ reduction of $\mathrm{R} 134 \mathrm{a}$.

The cooling capacity measurements are validated by a power meter that registers the electrical power consumption of the heaters. Figure 10 shows the evaporator heat balance for all the refrigerants tested. The measurements provide a good correlation between the measured heating power and cooling capacity. The deviation between both values always remains below $10 \%$ and is below $5 \%$ for middle evaporating temperatures greater than $-10{ }^{\circ} \mathrm{C}$. The deviation is greater at lower middle evaporating temperatures due to the greater effect of losses to the ambient at low cooling capacity values. 


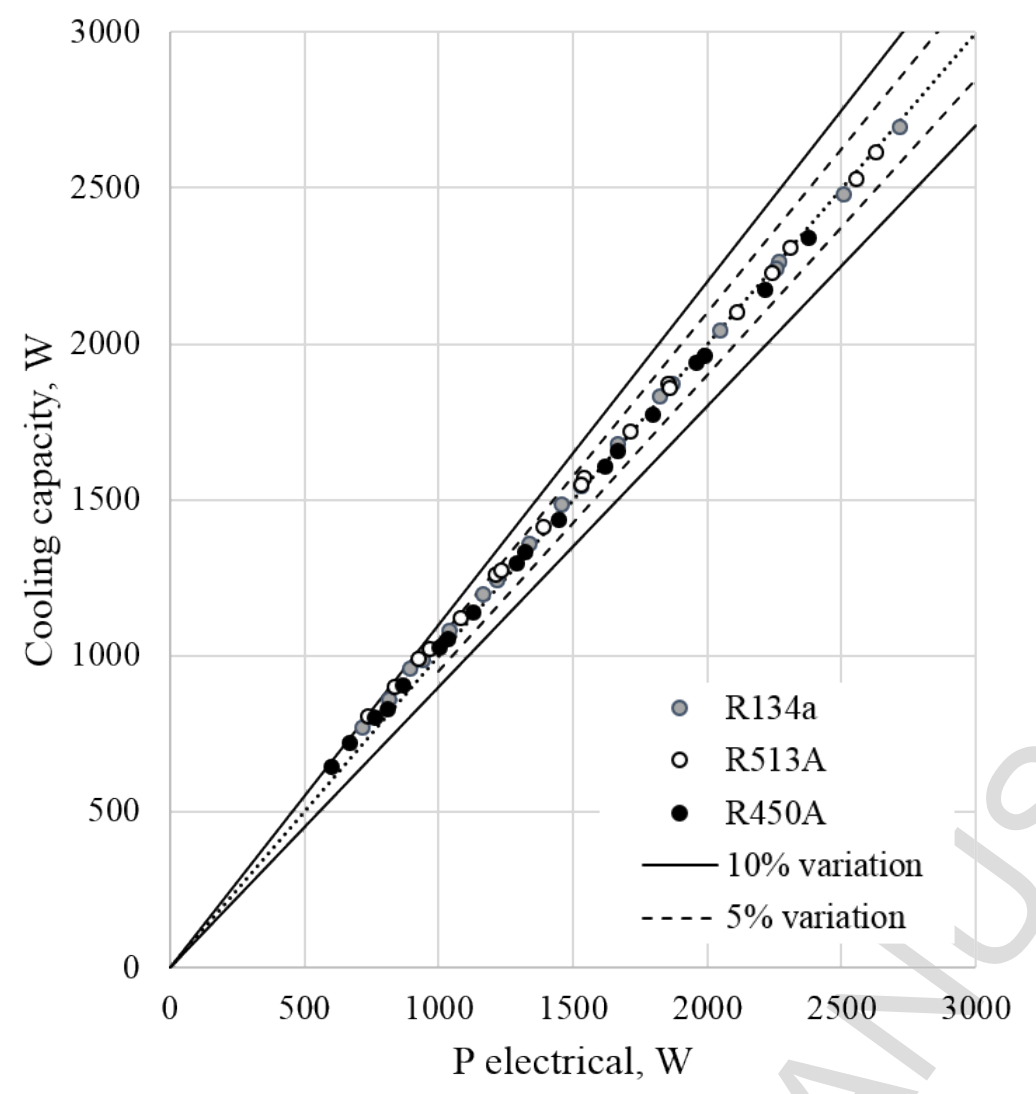

Figure 10 - Evaporator heat balance.

Then, dividing the cooling capacity values by the compressor power consumption, the coefficient of performance (COP) of the system is obtained, Equation 5. The COP and measured compressor power consumption values are presented in Figure 11 and Figure 12, respectively.

$$
C O P=\dot{Q}_{\text {evap }} / P_{\text {comp }}
$$




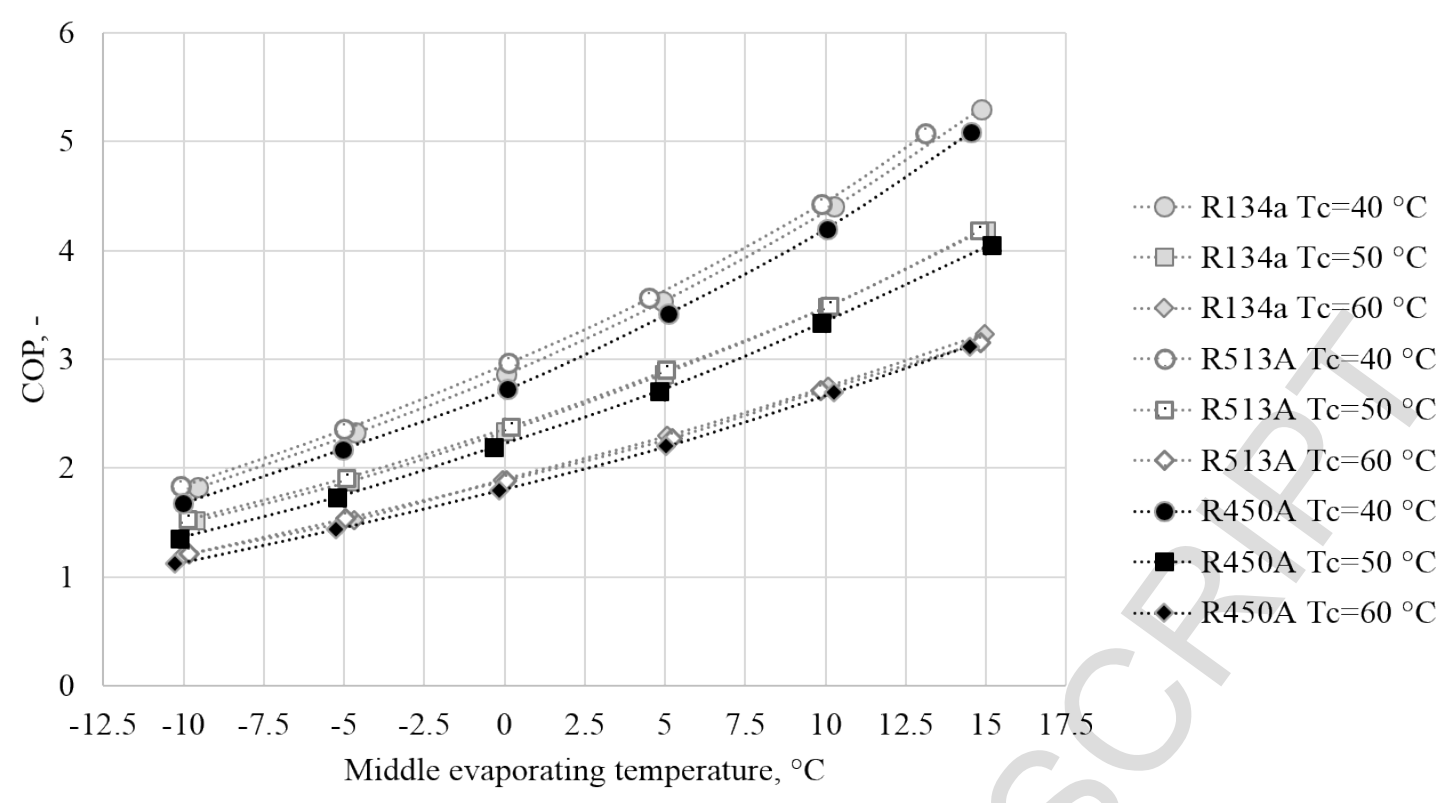

Figure 11. COP at the tested conditions.

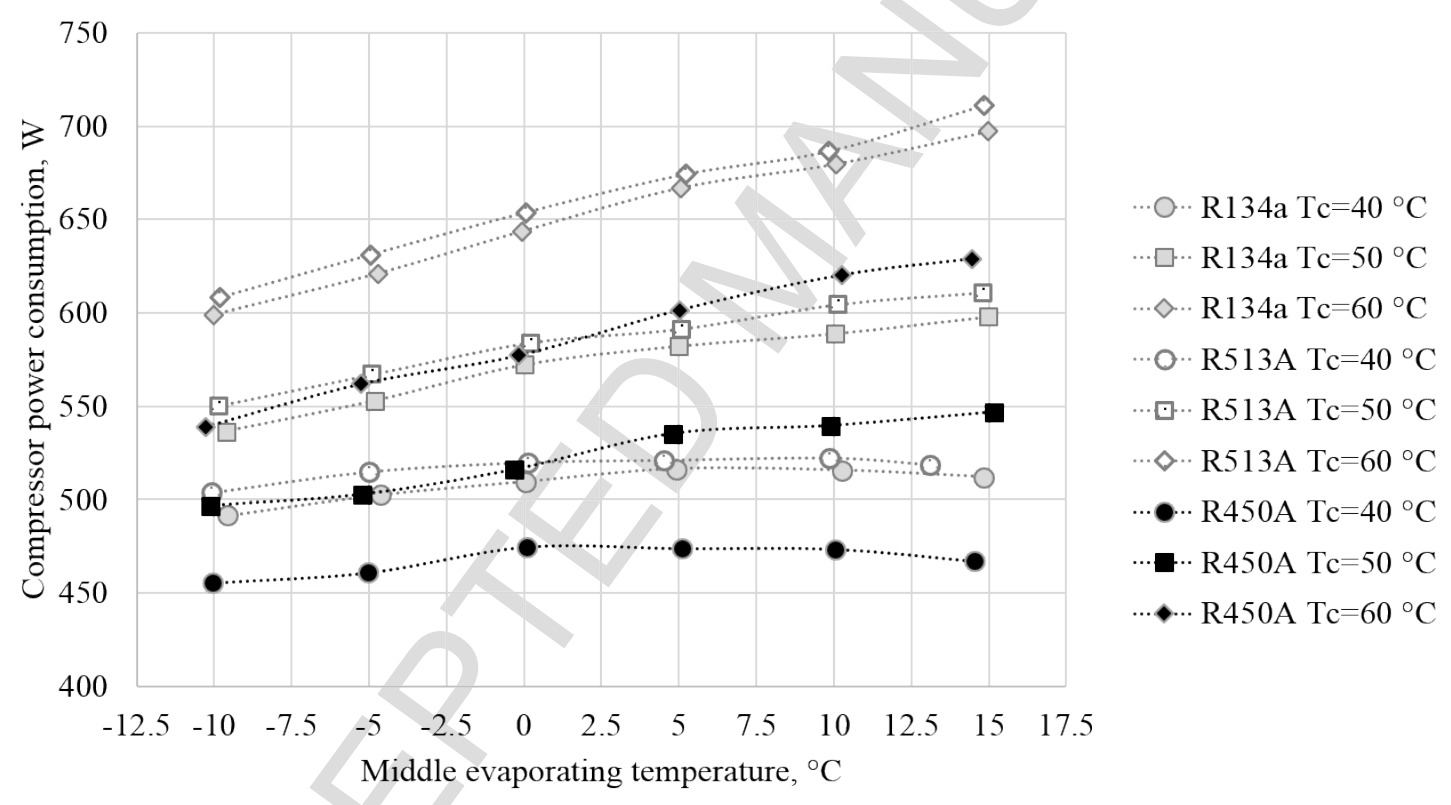

Figure 12. Power consumption at the tested conditions.

Under comparable conditions, the compressor power consumption, Figure 12, is significantly lowered when using R450A with respect to the alternatives. On average, $8.7 \%$ reduction from R134a baseline value is observed, with a higher reduction in higher middle condensing temperatures. The compressor power consumption at HATs is increased for every analyzed refrigerant. The increase is greater for the alternatives R450A and R513A (26\% and 28\%, respectively) than for $\mathrm{R} 134 \mathrm{a}(22 \%)$.

However, the reduced power consumption is not sufficient to fully compensate the cooling capacity reduction, and thus the energy performance of the system (expressed as COP) degrades 
with increasing middle condensing temperatures as a result of compressor power consumption change, Figure 12, and respective cooling capacity reduction. The resulting COP values of R450A are on average $5.3 \%$ lower than that of R134a. The power consumption of R513A is on average $1.8 \%$ higher than that of R134a but taking into account the higher cooling capacity obtained with this refrigerant, the resulting COP values are on average equal to that of R134a.

Taking into account the respective reduction of cooling capacity at HAT conditions, the magnitude of COP reduction at HATs is greater for the refrigerants R134a and R450A (35\% and $36 \%$ reduction for $\mathrm{R} 450 \mathrm{~A}$ and $\mathrm{R} 513 \mathrm{~A}$, respectively), whereas such change for $\mathrm{R} 450 \mathrm{~A}$ is slightly lower ( $35 \%$ reduction). The maximum uncertainty of the COP is $0.6 \%$

\section{5. $\mathrm{CO}_{2}$ equivalent emissions comparison}

The total equivalent warming impact (TEWI) metric is used to obtain the total $\mathrm{CO}_{2}$ equivalent emissions during the refrigeration unit operation. It takes into account both direct (due to leakages) and indirect (electricity consumption) emissions due to the use of a refrigeration system (European Committee for Standardization/Technical Committee, 2016).

The TEWI analysis has been performed according to the methodology listed in EN 378-1:2016 standard (European Committee for Standardization/Technical Committee, 2016), Equation 6, and the main assumptions are extracted from the LCCP guideline (IIR, 2016).

$$
T E W I=G W P \cdot L \cdot n+G W P \cdot m \cdot\left(1-\alpha_{\text {recovery }}\right)+n \cdot E_{\text {annual }} \cdot \beta
$$

The carbon intensity of electricity generation (due to combustion only) used at low voltage is acquired from Mora and Lonzo (2017) for a location in Spain. The annual energy consumption is calculated through the measured energetic parameters assuming continuous operation at $60 / 0{ }^{\circ} \mathrm{C}$ and at $40 / 0{ }^{\circ} \mathrm{C}$ middle condensing/evaporating temperature conditions.

The product of GWP, $L$ and $n$ represents the impact of leakage losses; the impact of recovery losses is calculated as $G W P \cdot m \cdot\left(1-\alpha_{\text {recovery }}\right)$ and the product of $n, E_{\text {annual }}$ and $\beta$ equates in $\mathrm{CO}_{2 \mathrm{eq}}$ equivalent impact of refrigeration system energy consumption during its operation time. The magnitudes of these contributing impacts are shown separately in Table 5 that contains the resulting TEWI at the proposed conditions and assumptions.

Table 5. TEWI analysis results

\begin{tabular}{|c|c|c|c|c|c|c|}
\hline \multirow[t]{2}{*}{ Refrigerant } & R134a & R450A & R513A & R134a & R450A & R513A \\
\hline & \multicolumn{3}{|c|}{$\mathrm{Tc}=40^{\circ} \mathrm{C}$} & \multicolumn{3}{|c|}{$\mathrm{Tc}=60^{\circ} \mathrm{C}$} \\
\hline $\begin{array}{l}\text { Impact of leakage losses, } \\
\mathrm{kg} \mathrm{CO}_{2 \mathrm{eq}}\end{array}$ & 171 & 82 & 86 & 171 & 82 & 86 \\
\hline $\begin{array}{l}\text { Impact of recovery losses, } \\
\mathrm{kg} \mathrm{CO}_{2 \mathrm{eq}}\end{array}$ & 68 & 33 & 34 & 68 & 33 & 34 \\
\hline $\begin{array}{l}\text { Impact of energy } \\
\text { consumption, } \mathrm{kg} \mathrm{CO}_{2 \mathrm{eq}}\end{array}$ & 19218 & 17901 & 19597 & 24272 & 21765 & 24659 \\
\hline
\end{tabular}




$\begin{array}{lllllll}\text { TEWI, kg CO } & 19457 & 18015 & 19718 & 24511 & 21880 & 24779 \\ \text { TEWI }_{\text {norm }}, \mathrm{kg} \mathrm{CO}_{2 \mathrm{eq}} \mathrm{kW}^{-1} & 13337 & 13945 & 12791 & 20136 & 21111 & 20087\end{array}$

According to the TEWI analysis, the impact of the leakage and recovery losses is reduced when using alternative refrigerants with lower GWP. As for the impact of energy usage, the $\mathrm{CO}_{2 \mathrm{eq}}$ emissions from R450A system are lower than that of baseline R134a and alternative R450A at the analyzed conditions. However, the R450A system delivers the lowest cooling capacity among the three refrigerants.

The results of TEWI has been normalized to the cooling capacity of the respective refrigerant in order to obtain TEWI of the refrigeration system calculated per $\mathrm{kW}$ of delivered cooling capacity. The resulting $\mathrm{TEWI}_{\text {norm }}$ indicates that, at the comparable amount of cooling provided over the lifetime of a system, R513A system will have the lowest contribution to global warming mainly due to the reduced impact of leakage and recovery losses. The reduction in $\mathrm{TEWI}_{\text {norm }}$ for R513A is particularly noticeable at a lower middle condensing temperature $(4.8 \%)$, whereas the reduction at a middle condensing temperature of $60{ }^{\circ} \mathrm{C}$ is only $0.2 \%$. R450A based system is penalized by the reduced energy efficiency at the compared operation conditions resulting in a 4.6 and $4.8 \%$ higher TEWI $\mathrm{norm}_{\text {at }}$ a 40 and $60^{\circ} \mathrm{C}$ middle condensing temperatures, respectively.

\section{Conclusions}

The high ambient temperatures (HAT) concern in several developing countries has been identified by the global environmental protection committees. To phase out the use of ozone depleting and/or global warming working fluids in refrigeration fluids, natural or synthetic lower GWP options can be considered. This paper compares the experimental operation of a small capacity refrigeration system using R134a and two alternatives with lower GWP, R513A and R450A, operating at middle evaporation temperatures between -10 and $15{ }^{\circ} \mathrm{C}$, and middle condensation temperatures of 40,50 and $60{ }^{\circ} \mathrm{C}$. It includes a previous thermodynamic assessment and then focuses on the discussion of operating and energetic performance experimental results. Then, energetic results are used to calculate the environmental impact of the considered working fluids on a typical small refrigeration system located in a HAT country.

R513A results favored from the operation analysis, attending to the different parameters analyzed. Pressure ratio parameter favors R513A, since is $8.9 \%$ lower than R134a on average, being that of R450A 3.5\% higher. Then, the maximum discharge temperature reached at the greatest compression ratio tested $\left(-10^{\circ} \mathrm{C}\right.$ middle evaporating and $60^{\circ} \mathrm{C}$ middle condensing temperature) is 98.6, 93.1 and $88.4{ }^{\circ} \mathrm{C}$, observed for R134a, R450A and R513A. According to that expected by the analysis of suction density, R450A mass flow rate is on average $9.2 \%$ lower than R134a and $\mathrm{R} 513 \mathrm{~A}$ is on average $19.3 \%$ higher. The refrigerant pipelines velocities are slightly lowered for R450A and increased for R513A at these conditions. 
Then, for this drop-in replacement, the energetic parameters also favor R513A out of the two alternatives. The volumetric and the cooling capacity of R513A is on average 1.5 and $2.5 \%$ higher than R134a, respectively, being those of R450A 7.0 and 14.3\% lower, respectively. As a result, $\mathrm{R} 513 \mathrm{~A}$ average COP is $1.8 \%$ greater than that of $\mathrm{R} 134 \mathrm{a}$, but the $\mathrm{R} 450 \mathrm{~A}$ average value is reduced by $5.3 \%$ in comparison with the HFC. For all the refrigerants COP is significantly reduced when changing the middle condensation temperature from 40 to $60^{\circ} \mathrm{C}$, being the greatest reduction for R513A, 36\%, and the lowest for R450A, 35\%.

The resulting experimental values are used to perform a TEWI analysis of a small capacity refrigeration unit at 40 and $60{ }^{\circ} \mathrm{C}$ middle condensation temperatures. For all the cases the direct emission values are low due to the small refrigerant leakage amount, such as the greater part of the environmental benefit comes from the energy efficiency variation between refrigerants. R450A produces $\mathrm{CO}_{2}$ equivalent emissions saving using conventional TEWI analysis, but leads to reduction in cooling capacity of such system. The normalized TEWI analysis (e.g. considering refrigerant cooling capacity variation) is used to simulate an environmental impact of a system at a real drop-in replacement and indicates that $\mathrm{R} 513 \mathrm{~A}$ produces greater than $\mathrm{R} 134 \mathrm{a} \mathrm{CO} \mathrm{C}_{2}$ equivalent emissions saving at lower condensation conditions, but only slight reduction at $60{ }^{\circ} \mathrm{C}$ middle evaporating conditions.

\section{Acknowledgements}

This research is done within the Effsys Expand P08 project that is funded by the Swedish Refrigeration Cooperation Foundation, KYS and Swedish Energy Agency with the support of Bosch Thermoteknik AB, Danfoss Värmepumpar AB, Nibe AB, Nowab, Svensk Energi \& Kylanalys $\mathrm{AB}$ and Svenska Kyltekniska Föreningen. Adrián Mota-Babiloni would like to acknowledge the funding received from the Spanish State Research Agency through the "Juan de la Cierva - Formación 2016" postdoctoral grant (FJCI-2016-28324). Alejandro López-Belchí would like to acknowledge the funding received from the "Fundación Séneca" through the regional program " Jiménez de la Espada" mobility grant (ref: 20135/EE/17).

\section{References}

AHRI, 2015. Participants' Handbook: AHRI Low GWP Alternative Refrigerants Evaluation Program.

Aprea, C., Maiorino, A., 2011. An experimental investigation of the global environmental impact of the R22 retrofit with R422D. Energy 36, 1161-1170.

doi:10.1016/J.ENERGY.2010.11.032

Aprea, C., Greco, A., Maiorino, A., 2017a. An experimental investigation of the energetic performances of HFO1234yf and its binary mixtures with HFC134a in a household refrigerator. Int. J. Refrig. 76, 109-117. doi:10.1016/j.ijrefrig.2017.02.005 
Aprea, C., Greco, A., Maiorino, A., 2017b. Comparative performance analysis of HFO1234ze/HFC134a binary mixtures working as a drop-in of HFC134a in a domestic refrigerator. Int. J. Refrig. 82, 71-82. doi:10.1016/j.ijrefrig.2017.07.001

Aprea, C., Greco, A., Maiorino, A., 2018. HFOs and their binary mixtures with HFC134a working as drop-in refrigerant in a household refrigerator: energy analysis and environmental impact assessment, Appl. Therm. Eng. 141, 226-233, doi:10.1016/j.applthermaleng.2018.02.072

ASHRAE, 2016. ANSI/ASHRAE Standard 34-2016. Designation and safety classification of refrigerants.

Devecioğlu, A., Oruç, V., 2018. Improvement on the energy performance of a refrigeration system adapting a plate-type heat exchanger and low-GWP refrigerants as alternatives to R134a. Energy 155, 105-116. doi:10.1016/J.ENERGY.2018.05.032

Eyerer, S., Eyerer, P., Eicheldinger, M., Tübke, B., Wieland, C., Spliethoff, H. 2018. Theoretical analysis and experimental investigation of material compatibility between refrigerants and polymers. Energy. Accepted manuscript. doi: 10.1016/J.ENERGY.2018.08.142

European Committee for Standardization/Technical Committee, 2016. SS EN 378-1:2016 Refrigerating systems and heat pumps - Safety and environmental requirements - Part 1: Basic requirements, definitions, classification and selection criteria.

European Parliament and the Council of the European Union, 2014. Regulation (EU) No 517/2014 of the European Parliament and of the Council on flourinated greenhouse gases. Off. J. Eur. Union 195-230.

Gill, J., Singh, J., Ohunakin, O.S., Adelekan, D.S., 2018. J. Exergy analysis of vapor compression refrigeration system using R450A as a replacement of R134a. Therm. Anal. Calorim. 1-16. doi: 10.1007/s10973-018-7675-z

GISTEMP Team, 2018. GISS Surface Temperature Analysis (GISTEMP). [WWW Document]. NASA Goddard Inst. Sp. Stud. URL https://data.giss.nasa.gov/gistemp/ (accessed 3.8.18).

Hu, J., Wan, D., Li, C., Zhang, J., Yi, X., 2010. Forecast of Consumption and Emission of HFC134a Used in the Mobile Air-conditioner Sector in China. Adv. Clim. Chang. Res. 1, 20-26. doi:10.3724/SP.J.1248.2010.00020

IIR, 2016. Guideline for Life Cycle Climate Performance v1.2.

IIR/IIF, 2017. The impact of the refrigeration sector on climate change, 35th Note on Refrigeration Technologies.

Intergovernmental Panel on Climate Change, 2014. Climate Change 2013 - The Physical Science Basis: Working Group I Contribution to the Fifth Assessment Report of the Intergovernmental Panel on Climate Change. Cambridge University Press, Cambridge. doi:10.1017/CBO9781107415324

Joudi, K.A., Al-Amir, Q.R., 2014. Experimental Assessment of residential split type airconditioning systems using alternative refrigerants to R-22 at high ambient temperatures. Energy Convers. Manag. 86, 496-506. doi:10.1016/j.enconman.2014.05.036 
Kontomaris, K., Kulankara, S., Kauffman, J.P., 2013. A reduced global warming potential replacement for HFC-134a in centrifugal chillers: XP10 measured performance and projected climate impact. HVAC\&R Res. 19, 857-864. doi:10.1080/10789669.2013.832361

Lemmon, E.W., Huber, M.L., McLinden, M.O., 2013. NIST Standard Reference Database 23: Reference Fluid Thermodynamic and Transport Properties (REFPROP), Version 9.1. Phys. Chem. Prop.

Leportier, R., 2018. ASERCOM2018 convention. Low GWP Refrigerants -Where do we stand.

Makhnatch, P., Mota-Babiloni, A., Khodabandeh, R., 2017. Experimental study of R450A dropin performance in an R134a small capacity refrigeration unit. Int. J. Refrig. 84, 26-35. doi:10.1016/j.ijrefrig.2017.08.010

Mastrullo, R., Mauro, A.W., Vellucci, C., 2016. Refrigerant Alternatives for High Speed Train A/C Systems: Energy Savings and Environmental Emissions Evaluation under Variable Ambient Conditions. Energy Procedia 101, 280-287. doi:10.1016/j.egypro.2016.11.036

Mendoza-Miranda, J.M., Mota-Babiloni, A., Ramírez-Minguela, J.J., Muñoz-Carpio, V.D., Carrera-Rodríguez, M., Navarro-Esbrí, J., Salazar-Hernández, C., 2016. Comparative evaluation of R1234yf, R1234ze(E) and R450A as alternatives to R134a in a variable speed reciprocating compressor. Energy 114, 753-766. doi:10.1016/j.energy.2016.08.050

Moffat, R.J., 1988. Describing the uncertainties in experimental results. Exp. Therm. Fluid Sci. 1, 3-17. doi:10.1016/0894-1777(88)90043-X

Moro, A., Lonza, L., 2017. Electricity carbon intensity in European Member States: Impacts on GHG emissions of electric vehicles. Transp. Res. Part D Transp. Environ.

doi:10.1016/j.trd.2017.07.012

Mota-Babiloni, A., Belman-Flores, J.M., Makhnatch, P., Navarro-Esbrí, J., Barroso-Maldonado, J.M., 2018. Experimental exergy analysis of R513A to replace R134a in a small capacity refrigeration system. Energy 162, 99-110. doi: doi.org/10.1016/j.energy.2018.08.028

Mota-Babiloni, A., Makhnatch, P., Khodabandeh, R., Navarro-Esbrí, J., 2017a. Experimental assessment of R134a and its lower GWP alternative R513A. Int. J. Refrig. 74, 680-686. doi:10.1016/j.ijrefrig.2016.11.021

Mota-Babiloni, A., Makhnatch, P., Khodabandeh, R., Navarro-Esbrí, J., 2017b. Experimental assessment of R134a and its lower GWP alternative R513A. Int. J. Refrig. 74, 682-688. doi:10.1016/ j.ijrefrig.2016.11.021

Mota-Babiloni, A., Navarro-Esbrí, J., Barragán-Cervera, Á., Molés, F., Peris, B., 2015a. Analysis based on EU Regulation No 517/2014 of new HFC/HFO mixtures as alternatives of high GWP refrigerants in refrigeration and HVAC systems. Int. J. Refrig. 52, 21-31. doi:10.1016/j.jirefrig.2014.12.021

Mota-Babiloni, A., Navarro-Esbrí, J., Barragán-Cervera, Á., Molés, F., Peris, B., 2015b. Dropin analysis of an internal heat exchanger in a vapour compression system using R1234ze(E) and R450A as alternatives for R134a. Energy 90, 1636-1644. doi:10.1016/j.energy.2015.06.133 
Ozone Secretariat, 2018. The montreal protocol on substances that deplete the ozone layer [WWW Document]. URL http://ozone.unep.org/en/treaties-and-decisions/montreal-protocolsubstances-deplete-ozone-layer (accessed 3.8.18).

Ribeiro, G.B., 2016. A novel vapor-compression refrigeration loop for high ambient temperatures. Int. J. Refrig. 70, 103-107. doi:10.1016/ j.ijrefrig.2016.07.004

Seidel, S., Huang, J., Andersen, S.O., 2016. International approaches to structuring a high ambient temperature exemption.

UNEP Technology and Economic Assessment Panel, 2015. Update XXVI/9 Task Force Report. Additional information on alternatives to ozone-depleting substances.

United Nations, 2018. Greenhouse Gas Inventory Data - Global map - Annex I [WWW Document]. URL http://di.unfccc.int/global_map (accessed 3.21.18).

US EPA, 2017. Overview of SNAP [WWW Document]. URL https://www.epa.gov/snap/overview-snap (accessed 4.12.18). 
R450A and R513A as lower GWP mixtures for high ambient temperature countries: experimental comparison with R134a

\section{HIGHLIGHTS}

- R450A and R513A are analyzed as drop-in replacements to R134a.

- Selected middle condensing temperatures are 40,50 and $60{ }^{\circ} \mathrm{C}$.

- R513A and R450A shows proper adaptation to R134a system.

- R513A energy performance is comparable to R134a at most conditions.

- Normalized TEWI gives better results for R513A. 